\title{
Raça, gênero, classe e estupro: exclusões e violências nas relações entre nativos e turistas em Florianópolis
}

FLÁVIA DE MATTOS MOTTA*

Este trabalho apresenta o caso de Jairo. Nascido em Florianópolis, negro, filho de uma empregada doméstica, Jairo testemunha, em sua história de vida, a exclusão econômica, social e racial: na infância, abandona a escola na quarta série sem ter sido alfabetizado; na adolescência, trabalhando na construção civil e biscates, não se adapta ao mundo do trabalho e, aos poucos, se inicia nas contravenções e pequenos crimes (uso de drogas, pequenos furtos). Aos 19 anos é preso (espancado), julgado e condenado a 17 anos de prisão por haver espancado, roubado e estuprado uma turista (branca, classe média) entre as dunas próximas à sua casa quando esta voltava da praia. Mesmo considerando-se o caso como exemplar das mais bárbaras formas de violência contra a mulher, as quais se pretende combater, a abordagem deste trabalho está focada em outra questão. Esse caso dá visibilidade a uma determinada dimensão das relações entre nativos e estrangeiros no cenário paradisíaco das praias de Florianópolis: a dimensão violenta dessas relações - para as quais concorrem (em certos casos, cumulam) os aspectos raça, cultura, classe e gênero.

Palavras-chave: Raça; cultura; classe; gênero; estupro; violência.

Recebido em: 27/10/2005.

Aprovado em: 22/02/2006. 
Ninguém sentiu o teu espasmo obscuro, Ó ser humilde entre os humildes seres. Embriagado tonto dos prazeres, $O$ mundo para ti foi negro e duro. (...) Ninguém te viu o sentimento inquieto, Magoado, oculto e aterrador, secreto Que o coração te apunhalou no mundo. Mas eu que sempre te segui os passos, sei que cruz infernal prendeu-te os braços, e o teu suspiro como foi profundo

Cruz e Souza ${ }^{1}$, Vida Obscura

Este trabalho ${ }^{2}$ está baseado num capítulo da tese (MOTTA, 2002) na qual trabalhamos com os chamados "nativos de Florianópolis (designação êmica que distingue aqueles que nasceram na cidade daqueles identificados como "o pessoal de fora"). Em Florianópolis, pesquisamos uma localidade turística à qual, por motivos éticos, demos o nome de "Paraíso". A discussão teórica desta pesquisa se desenvolveu em torno de dois eixos: gênero e reciprocidade. Analisando gênero, família e relações nativos/pessoal-de-fora, procuramos demonstrar que, no contexto estudado, gênero está englobado no princípio de reciprocidade que ordena as relações sociais.

No dia 20 de julho de 2001 ficamos sabendo que Jairo, um rapaz de 19 anos, filho de nossa principal informante, fora preso. Jairo estuprou violentamente uma turista, moça de vinte e poucos anos ( 23 ou 27 , dependendo da versão) vinda de outro estado do país para passar uns dias numa praia durante as férias de julho. Quando ela voltava da praia, atalhando caminho entre dunas, ele a atacou, espancou-a brutalmente, estuprou-a, roubou-lhe o relógio de pulso e deixou-a sem sentidos na areia.

Logo que soubemos do brutal crime que Jairo cometera, tentamos reacomodar em nossa razão a imagem que tínhamos dele até então - o lindo menino negro que conhecemos com cerca de 15 anos, sempre um pouco distante, de olhar entre perscrutador e dissimulado, sempre pronto para um chiste e dono de um sorriso encantador. Quando tentávamos racionalizar o que havia acontecido - esse menino "nativo" transformado num estuprador feroz, espancando, violentando e abandonando a vítima, uma moça vinda "de fora", inconsciente e, segundo uma versão, supondo-a morta - era a história do Capitão Cook - feita parábola - que vinha à mente. A história do capitão Cook, em que 
o explorador, não sabendo observar as regras de reciprocidade de seus amigos nativos havaianos, acabou sendo assassinado pelos mesmos, tornando-se uma espécie de paradigma na Antropologia ${ }^{3}$ - especialmente para a discussão que aqui interessa: a reciprocidade. Perguntávamos então: será que, quando os "nativos" não matam o Capitão Cook, estupram suas filhas?

Como qualquer caso de estupro, estamos diante do que chamamos "dominação masculina" (BOURDIEU, 1998). Nas situações em que "um homem grande bate numa mulher pequena", verificam-se - à semelhança do caso melanésio (STRATHERN, 1988) - dominações que se dão no plano das relações interpessoais (do masculino sobre o feminino), mas o caso nos permite refletir sobre outras dominações além das de sexo/gênero. Quando um "nativo" (excluído, pobre e negro) violenta uma "turista" (branca e pertencente a uma classe que representa tudo aquilo a que o primeiro não tem acesso, desde bens materiais até poder e capital simbólico), o dado de campo extrapola as "relações pessoais", autorizando-nos a refletir sobre o que nele há de simbólico, inclusive além do âmbito estrito das "relações de gênero". Essa linha de análise não é desprezível e não pretende obliterar análises de gênero, especialmente aquelas que sublinham as relações de gênero como relações de poder e a violência contra a mulher como parte de relações de dominação (SUÁREZ; BANDEIRA, 1999). Pretendemos demonstrar aqui o que esse crime - para além da evidente manifestação de "dominação masculina" - tem de revelador a respeito das consequiências da exclusão social que é conhecida pelas camadas empobrecidas em Florianópolis, incluindo "nativos".

\section{Jairo}

Jairo é negro (e poderíamos dizer, parafraseando o título de um importante estudo local [PEDRO, 1988], é um "negro em terra de branco") e com certeza experimentou todas as limitações que os preconceitos locais impõem aos afrodescendentes. O segmento residencial familiar (RIAL, 1988) onde mora fica numa área semi-rural (ou semi-urbana), às margens de uma rodovia estadual entre duas famosas e freqüentadas praias da ilha (uma delas, especialmente famosa, com um perfil plenamente turístico e balneário, e a outra apresentando mais claramente aquela característica de balneário e bairro de moradia de famílias de classe média vindas "de fora"). ${ }^{4}$

Estudou até a quarta série, mas não aprendeu a ler nem a escrever nada além do próprio nome. Desde os sete anos, cresceu junto com a irmã, 
Lulu, dois anos mais jovem, na casa de Deca, com quem sua mãe, Marlene, se casou (informalmente). Deca é um homem branco, poucos anos mais jovem que Marlene, e logo construiu uma relação paternal muito afetiva com a caçula, Lulu, que, em comparação com o irmão, pode ser vista como um modelo de filha - aplicada aos estudos, adaptada à rotina da escola, dos afazeres domésticos e, desde os 16, ao trabalho como empregada doméstica. Jairo, ao contrário, nunca se adaptou à disciplina escolar (ou talvez fosse mais exato dizer o contrário: a escola foi refratária a Jairo e a suas dificuldades de aprendizado).

Talvez por coisas desse tipo, Jairo não conquistou a mesma simpatia que a irmã obteve do padrasto, que, segundo nos contou uma amiga da família, o espancava quando pequeno. Jairo tampouco se adaptou à disciplina e à ética do trabalho. Às vezes a própria mãe se empenhava em "arrumar algum serviço para ele", mas ele logo o abandonava (em geral, ficava alguns meses ou dias num canteiro de obra como servente, mas, certa vez, fui atendida por ele num posto de gasolina no Paraíso) e aí, conforme as palavras de Marlene, "passava um tempo na rua" quando então, segundo Lulu, "andava com os mala $^{5}$ do Paraíso". Essas "más companhias" de Jairo são jovens como ele, a maioria menor de idade, que se dedicam a pequenos furtos (walkman, relógios, tênis de marca e pequenos roubos de mercadorias em mercados locais). Em comum com esses amigos, mas também com boa parte do "pessoal de fora" do Paraíso, acrescenta-se o consumo de maconha.

Quando estuprou a turista (uma moça branca), estava com 19 anos, trabalhava como servente de obras, estava casado com Carla (21 anos) e seu filho tinha 7 meses. Os três moravam numa casinha construída nos fundos da casa de Marlene e Deca. No dia do crime, Jairo trabalhou toda a manhã na obra e, ao meio-dia, atacou a moça. Depois foi almoçar com os familiares, que - tendo ele se desfeito de suas roupas ensangüentadas, que depois serviriam de provas contra ele - nada notaram que pudesse sugerir mudança de rotina (a não ser por um relógio que aparecera sobre o balcão da cozinha).

\section{Violência, hierarquias e reciprocidade}

É certo que temos um terreno fértil para discussões sociológicas e psicológicas. Não pretendo ceder a elas. Mas, se mantivermos a história de Cook como parábola e retomarmos a discussão teórica nos termos de Bourdieu acerca da economia das trocas simbólicas, particularmente o tocante ao 
mascaramento das relações de "exploração" entre as partes envolvidas na toca (e a violência simbólica aí implicada), fica a sugestão de que a troca não implica necessariamente igualdade entre os que trocam. E mais: a troca pode ser violentamente extorquida se não é aceita de comum acordo ou se uma das partes se sente permanentemente lesada.

A violência pode ser pensada também como dádiva? Uma dádiva que leva ao extremo a tradução do termo gift como veneno, eliminando assim a ambivalência intrínseca da dádiva que faz dela veneno e remédio (CAILLÉ, 1998, p. 16). Talvez aqui fosse útil a noção de "dádiva negativa" (dádiva dos males e da morte), que se opõe à de "dádiva positiva" (dádiva de bens) - noções essas que Caillé (1998. p. 21) utiliza apenas ao referir "belo livro" de Dominique Temple e Mirreille Chabal (1995) sem, no entanto, se deter sobre elas.

Em seu livro A divida divina, em que trata das relações entre troca e patronagem no Nordeste brasileiro, Marcos Lanna faz algumas observações acerca da relação dádiva/violência.

Surge assim um sistema de mercado basicamente específico, no qual tanto as relações patrão-empregado como as interpatronais são concebidas pela dádiva e pela dívida como uma forma de dádiva. Como foi dito, tal fato não exclui a presença de força, de arbitrariedade e de toda a sorte de constrangimentos, que incluem rivalidades interpatronais, isto é, não se resumem à violência do patrão em relação a seus empregados. Lembro que as relações de troca de dádiva não excluem, mas pressupõem a rivalidade, podendo assumir caráter mais ou menos agonístico ou, mesmo, competitivo (cf. MAUSS, 1974).

A violência é assim fundamental para a própria constituição das estruturas de troca de dádivas que organizam as relações entre patrões e aquelas dos patrões com seus empregados (LANNA, 1995, p. 32).

Para Lanna, a hierarquia no Nordeste pressupõe violência e arbitrariedade e se nutre das relações de classe. $\mathrm{O}$ autor procura demonstrar "a possibilidade da existência de uma síntese entre hierarquia, violência e relações de classe", recaindo a ênfase de sua análise no primeiro desses termos (LANNA, 1995, p. 46). ${ }^{6}$

Bourdieu (1998) estabeleceu a relação entre a troca, a dominação/ exploração e a violência simbólica. Mas aqui estamos falando em algo mais 
que violência simbólica. A violência de que se trata aqui envolve violência física. Jacques Godbout, em seu livro $O$ espírito da dádiva (que fez em colaboração com Alain Caillé), faz a pergunta "E a violência?" (GODBOUT, 1999, p. 240), embora, em nosso entender, sem se deter tampouco satisfatoriamente sobre ela: ${ }^{7}$

Mas que vínculo existe entre a dádiva e a violência? Este livro não aborda a violência, nem mesmos os vínculos entre esses dois fenômenos. Notemos simplesmente que a dádiva é uma troca alternativa à violência, que se pode conceber a violência como o estado negativo de um sistema social que seria conseqüência da interrupção da dádiva. Isso não significa que dádiva e violência obedeçam às mesmas regras. [...]. O estado de não-dádiva é um estado de reserva, de retenção, de não-abandono, muito diferente da violência e não obedece à mesma lógica. Embora um nada possa levar à passagem de um estado a outro, esses dois estados não obedecem às mesmas regras. A violência e a dádiva são dois estados diferentes (GODBOUT, 1999, p. 242).

Sugiro que esse "nada" que faz com que dádiva se transmute em violência é justamente a lógica da reciprocidade que rege as relações sociais em dado contexto. Se consideramos que a dádiva é o que os homens "inventaram" para fugir à guerra (ou "que a dádiva é uma troca alternativa à violência"), parece lógico sugerir que a quebra da dádiva (da tríplice obrigação de, adequadamente, dar-receber-retribuir) conduza à "guerra", no limite, à violência - na medida em que essa quebra já é em si violenta. A violência e a dádiva "são dois estados diferentes", mas, tendo os dados desta pesquisa em mente, devemos considerá-los como regidos ambos pela lógica da reciprocidade. Então importa menos aqui decidir se violência é "dádiva" do que constatar que, como a "dádiva", a "violência", ao menos em certos contextos, como o campo que pesquisamos assinala, responde à lógica da reciprocidade, ou seja, obedece ao sistema dar-receber-retribuir.

Se aceitamos a possibilidade de pensar esse caso de estupro como, em certa instância, obedecendo a uma lógica de reciprocidade (a exemplo do assassinato de Cook), é necessário dizer que ele tampouco encerra o "ciclo da dádiva". Ao contrário, da forma como foi pensado pelos próprios nativos, exige um "contradom". "Ele tem que pagar" - dizia Lisa (21 anos), a amiga de Carla e Jairo. "É bom ele já levar um saco de calcinhas" - diziam rapazes amigos dos três, aludindo ao fato de que, uma vez no presídio, será transformado em 
"mulherzinha" da cela pelos demais apenados da mesma. Ou seja: Jairo terá de "pagar" pelo crime, não só com a privação de liberdade, conforme o juiz estabelecer, mas também com a sujeição ao mesmo suplício que sua vítima, de acordo com o código informal dos apenados relativo a crimes de estupro (e que, apesar de informal e ilegal, é socialmente reconhecido a ponto de as pessoas terem a expectativa de que ela se concretize) ${ }^{8}$ Antes do julgamento e antes mesmo de dividir cela com outros, Jairo já começou a "pagar", via espancamentos - os policiais o faziam pretensamente para obter confissão de outros estupros (já que aquele Jairo confessou imediatamente sem ser necessário qualquer tipo de violência). Mas por que outro motivo, que não o "pagar", ou seja, o acionamento da lógica de reciprocidade (presente inclusive em noções de honra), justificaria o fato dos policiais permitirem a entrada do namorado da moça na cela para bater em Jairo?

Estupro, sedução, defloramento, assédio sexual: certamente há significados diversos para as muitas categorias que se referem à "violência sexual", designação que poderia ser entendida também como "sexo roubado à mulher". A idéia de "sexo roubado" é descritiva em relação a um determinado aspecto da violência sexual, a ausência de consentimento da vítima. Roubo é o furto mediante violência. Nas várias formas de violência sexual algo está sendo roubado da vítima, e a ausência de consentimento e o abuso de poder significam violência.

Trata-se de situações em que alguém obtém sexo ou algum tipo de satisfação sexual - submetendo outra pessoa, usando o corpo de alguém contra a sua vontade, numa relação de poder desequilibrada ou de "quebra de contrato" - usando neste ponto a noção introduzida por Sophie Day (1994), a partir de seu estudo sobre as noções de estupro entre prostitutas inglesas. A categoria sexo roubado adquire sentido peculiar num contexto regido pela regras de reciprocidade, e particularmente numa história de vida marcada por uma seqüência de quebras dessas regras: quando pensamos em Jairo e sua gradativa incursão no mundo da contravenção - começando por cobiçar certos bens de consumo, furtando ou roubando relógios, aparelhos de som, mercadorias em mercadinhos locais e terminando por "roubar sexo", violentando uma mulher, um corpo que não lhe pertencia nem a seu mundo.

Em nenhum momento deixamos de pensar na moça aqui referida como "a turista" como a grande desse crime. Tampouco reduziríamos violência e estupro à exclusão social - como o incesto, o estupro está em todas as camadas 
de nossa sociedade. $\mathrm{O}$ fato de ter defendido os direitos humanos ${ }^{9}$ do estuprador, que vinha sendo espancado na delegacia em que esteve preso, ${ }^{10}$ também não significa que não desejássemos que seu crime fosse punido rigorosa e exemplarmente - dentro dos cânones legais. Hoje Jairo cumpre pena de 17 anos no presídio de Florianópolis.

O caso permite outras abordagens, mas a que cabia no âmbito de nossa pesquisa era a que o relacionava ao princípio da reciprocidade: "a troca", a reciprocidade como um instrumento fundamental para pensar a realidade que escolhemos estudar. Não se trata de querer desvendar "a lógica do estupro ou do estuprador", incorrendo num tipo de relativismo que aceita e por isso legitima a perpetuação de diversas violências contra a mulher. Trata-se de submeter algo ("imponderável") que aconteceu no desenrolar da pesquisa às hipóteses da mesma, isto é, verificar em que medida o evento aciona a lógica da reciprocidade - menos pela prática em si, mas pelas exegeses dos informantes a respeito do mesmo.

Diante de todos esses dados, tendo ainda em mente a exclusão social ${ }^{11}$ e a usurpação que os nativos - ou uma parcela deles - vêm conhecendo nas últimas décadas, e voltando à parábola do capitão Cook, faz sentido perguntar: será que, às vezes, os "nativos" (usurpados e excluídos) matam os capitães, enquanto em outras estupram suas filhas? Nós lhe damos o paraíso e, se nada vier em toca, matamos aquilo que você mais valoriza? ${ }^{12}$ Responder com uma simples afirmativa seria reducionista, mas a pergunta cabe ao menos como um alerta sobre as conseqüências da exclusão e desigualdade social, da especulação imobiliária inescrupulosa, do turismo crescente em áreas como Paraíso, a despeito dos "choques culturais"13 impostos às populações nativas sem projetos de educação, qualificação profissional e integração dos grupos às novas situações.

\section{Explicações nativas: reciprocidade}

É relevante registrar aqui duas explicações nativas que ouvimos para o ato de Jairo. Lisa, uma jovem empregada doméstica que morava com Jairo e Carla, ${ }^{14}$ após muitos rodeios e indiretas ("Ninguém entende como um homem faz isso se tem mulher em casa!"), acabou expondo sua teoria, que não deixa de nos remeter à lógica do dom. Confidenciou-me que Carla há meses (desde que o bebê nascera) negava-se a ter relações sexuais com Jairo: "Por que ela 
me dizia que para mais de dois meses que eles não tinham relações. [Ah, é? perguntamos.] É, e ele me disse que ela era uma morta. Então vai ver que ele fez isso por que estava assim, né?"' Lisa é tímida e lacônica, pergunto-lhe então se ela acha que ele fez aquilo porque não agüentou por estar "no atraso" e ela confirma: "porque um cara assim, né?".

A explicação de Lisa evoca a quebra do pacto de reciprocidade nas relações do casal. Mas a explicação de Deca é mais eloqüente na expressão da lógica da troca como o idioma mais adequado, em termos nativos, para, senão explicar, justificar o ato de Jairo, de certa forma atribuindo-lhe certa inevitabilidade diante de atitudes do "pessoal de fora", ou melhor, das mulheres de fora (que provocam uma reação, um troco). No dia em que fizemos a denúncia relativa a direitos humanos que resultou na interferência da Corregedoria de Polícia no caso, estivemos muitas horas com Marlene e Carla, e à noite as levamos casa. Lá chegando, pudemos assistir, ou participar, do reencontro da família (Deca, Marlene, Lulu, Carla e o bebê), quando colocaram a conversa em dia, trocaram informações e avaliações sobre os últimos acontecimentos e sobre o caso em si. Transcrevemos a seguir uma parte do registro de campo feito nesse dia, na qual Deca elabora sua própria teoria sobre o sentido daquele estupro dentro das relações entre os(as) "de fora" e os nativos.

Teve um momento em que se falou mais diretamente do estupro. Deca faz quase um monólogo, dizendo que 'também essa gurias vêm de fora e pensam que aqui é o quê? Ficam nuas e acham o quê? Ele fica rindo como quem não entende e acha graça de um hábito inexplicável de quem não mede as consequiências. Eu pergunto: peladas? E ele: é, cansei de ver, elas tiram tudo e ficam nuas lá nas dunas, eu cansei de ver, porque eu ando lá para aqueles lados porque eu levo vaca para lá (que tem uma parte que tem uns matos) e aí tem uns [usou uma palavra que eu não conheço mas explicou-me que quer dizer uma reentrância entre duas dunas maiores] no meio das dunas, e elas ficam ali. Eu cansei de ver, mas comigo não tem problema porque eu nunca... mas elas ficam lá peladas, os caras vêem, que que elas acham? Ele fala isso rindo e balançando a cabeça. Não é que ele ache que elas estão 'pedindo' para ser atacadas. A perplexidade de Deca diz respeito à incapacidade $^{15}$ das garotas de preverem o que aquilo pode provocar em certos homens (diferentes dele) que não estão acostumados com aquilo e que não têm a capacidade dele próprio de ver aquela cena e não se envolver com ela (Diário de campo. sexta feira, 20/07/2001). 
$\mathrm{O}$ argumento de Deca lembra tudo o que conhecemos a respeito das acusações que habitualmente recaem sobre as vítimas de estupro: ela provocou! Não obstante, devemos examinar a argumentação de Deca à luz de seus referenciais cognitivos. Nos termos nativos, de acordo com a lógica da reciprocidade que impera, uma coisa puxa a outra. Para Deca, a atitude de Jairo tinha algo de previsível, considerada como consequiência de atitudes das "gurias" de fora. Essa fala evoca vários episódios, alguns mais outros menos violentos, ocasionados pelo choque cultural entre nativos e aqueles chamados "de fora" - implicando valores morais, desde conflitos entre pescadores e nudistas na Praia da Galheta, até episódios como o relatado por Márcia Fantin, ocorrido no verão de 1980, em que um casal de amigos seus ("de fora") foi expulso de uma "vendinha", pelo dono do estabelecimento, de facão em punho, ao ver que os dois esperavam o atendimento aos beijos. O homem nativo gritava que a sua era uma "casa de respeito" e o casal da metrópole saiu comentando "Que cidade mais provinciana e atrasada!" (FANTIN, 2000, p. 37).

Gostaríamos de insistir na discussão sobre o que as duas explicações, de Deca e de Lisa, têm em comum. Ambas descrevem uma situação de negação da masculinidade: a mulher que não quer ter relações sexuais com marido depois que teve um filho e a mulher que fica pelada nas dunas como se não estivesse em presença de um portador de atributos de masculinidade. As duas estão falando, de maneiras diferentes, que houve uma quebra da lógica da reciprocidade, uma recusa da troca. Essa recusa é ofensiva, negativa. E uma coisa puxa a outra. $\mathrm{O}$ ciclo da troca se completa ${ }^{16}$ na forma da violência. Em certo sentido, esse caso de estupro revela uma situação em que as formas de classificação e hierarquização do mundo não funcionam. ${ }^{17}$ Só há "sexo", só há pulsão sexual, não há gênero, não há "relação de gênero" no sentido nativo: uma relação calcada na reciprocidade. É uma situação radicalmente diferente da violência ou das agressões físicas no casal tratadas por Gregori (1993) ou Grossi (1988).

Nessa medida, a explicação de Deca é muito distinta das visões do estupro que consideram que foi a vítima que provocou, porque tentou seduzir o agressor. O que ele está dizendo é que ela (a vítima) não percebia a existência de Jairo, do homem nativo. A troca não implica igualdade entre os que trocam, mas o reconhecimento de que há alguém a quem se dá ou de quem se recebe ou se espera retribuição. Deste ponto de vista, o estupro aparece, mais do que dádiva negativa, como a ausência de comunicação - é sexo roubado. É violência contra a mulher e é dominação masculina - as circunstâncias extremamente 
violentas e as seqüelas experienciadas pela vítima não deixam dúvidas sobre uma relação desigual de poder e força física.

\section{Considerações finais}

Esse caso dá visibilidade a uma determinada dimensão das relações entre nativos e estrangeiros no cenário paradisíaco das praias de Florianópolis: a dimensão violenta dessas relações - para as quais concorrem (em certos casos, cumulam) os aspectos raça, cultura, classe e gênero. A partir daí, descortinam-se elementos comuns a estudos que se detêm sobre a sociedade de classes brasileira: exclusão, direitos humanos, violência, raça e educação. ${ }^{18}$ Intentamos aqui uma abordagem capaz de ampliar os limites do campo de análise para além do óbvio e seguro, adentrando em campo sabidamente minado, mas acima de tudo desafiador e esclarecedor.

Deixando de lado seu aspecto mais aparente e investindo numa análise mais arriscada, mas não menos instigante, devemos investigar correlações, no tocante aos aspectos simbólicos, entre casos como esse estupro e o que vem sendo discutido a propósito do estupro de guerra (VIGARELLO, 1998): "Não apenas atinge corpo e psique de uma mulher: tem a conseqüência de desonrar e humilhar, mas também atingir uma suposta pureza étnica do povo representado pelas mulheres vitimadas e fertilizadas pelo inimigo" (MOTTA, 2006, s/p).

Evidentemente, se é que é possível aqui algum paralelo, o mesmo deve ser traçado com cautela. Não há, no caso descrito, "guerra" ou qualquer confronto declarado e organizado. Não há elementos aqui para supormos intenção de aniquilar geneticamente um grupo étnico ou social que a vítima representa. Mas, como outras manifestações da violência social interclasse e inter-racial no Brasil, esta toma a forma física (com o aspecto sexual particularizador ${ }^{19}$ e não se basta ou se detém ao obter algo que se pretende roubar. O agressor não parece apenas procurar prazer sexual, ele só se detém diante do jugo absoluto, a dominação total sobre o corpo e a vida da vítima, uma vez que a supôs morta.

Sugerimos que o crime relatado não possa ser de fato e de todo entendido se não olharmos para Jairo e tentarmos entender ele também como sujeito de relações desiguais de poder em que ele incorpora o fraco, relações de exclusão - referimo-nos às relações raciais, relações de classe social, mas também étnicas ou culturais. A investigação de casos semelhantes pode trazer 
esclarecimentos não apenas sobre a violência sexual como certos sentidos da violência social na sociedade brasileira.

\section{Referências}

BOURDIEU, P. La domination masculine. Paris: Seuil, 1998.

BRITES, J. Serviço doméstico: um outro olhar sobre a subordinação In: LISBOA, M. E. A.; MALUF, S. (Orgs.). Gênero, cultura e poder. Ilha de SC: Editora Mulheres, 2004. p. 111-143.

CAILLÉ, A. Nem holismo nem individualismo metodológicos: Marcel Mauss e o paradigma da dádiva. Revista Brasileira de Ciências Sociais, v. 13, n. 38, p. 5-37, out. 1998.

DAY, S. What counts as rape? Physical assault and broken contracts: Contrasting views of rape among London sex workers. In: HARVLEY, P.; GOW, P. (Eds.). Sex and violence. London: Routledge, 1994.

FANTIN, M. Cidade dividida. Florianópolis: Cidade Futura, 2000.

FONSECA, C; CARDARELLO, A. Direitos dos mais e menos humanos. Horizontes Antropológicos, ano 5, n. 10, Porto Alegre: PPGAS/UFRGS, 1999. p. 104-112.

GODBOUT, J. O espírito da dádiva. Rio de Janeiro: FGV, 1999.

GREGORI, M. F. Cenas e queixas: um estudo sobre mulheres, relações violentas e a prática feminista. Rio de Janeiro: Paz e Terra, 1993.

GROSSI, M. P. Discours sur les femmes battues: représentations de la violence sur les femmes au Rio Grande do Sul. Thèse (Doctorat) - Université Paris V, 1988.

LANNA, M. P. D. A divida divina: troca e patronagem no Nordeste Brasileiro. Campinas: Unicamp, 1995.

MAUSS, M. Ensaio sobre a dádiva, forma e razão da troca nas sociedades arcaicas. In: . Sociologia e Antropologia. v. 2. São Paulo. EPU, 1974. $326 \mathrm{p}$.

MOTTA, F. M. A morte e a janela: a idéia de morte em representações contemporâneas de estupro. In: . Saberes e fazeres de gênero: entre 
o local e o global. Florianópolis: Editora da UFSC. No prelo.

MOTTA, F. M. Gênero e reciprocidade: uma ilha no sul do Brasil. Tese (Doutorado em Ciências Sociais) - Universidade Estadual de Campinas, Campinas, 2002.

PEDRO, J. M. et al. Negro em terra de branco: escravidão e preconceito em Santa Catarina no século XIX. Porto Alegre: Mercado Aberto, 1988.

RIAL, C. S. Mar de dentro: o espaço social na Lagoa da Conceição. Dissertação (Mestrado em Antropologia Social) - Universidade Federal do Rio Grande do Sul, Porto Alegre, 1988.

SAHLINS, M. Ilhas de história. Rio de Janeiro: Zahar, 1997.

SILVA, E. A natureza cultural da Justiça: por uma teoria multidisciplinar da Justiça, vista através do ritual de violência sexual no presídio masculino de Florianópolis. Dissertação (Mestrado em Antropologia Social) - Universidade Federal de Santa Catarina, Florianópolis, 1997.

STRATHERN, M. The gender of the gift: problems with women and problems with society in Melanesia. Berkeley: University of California Press, 1988.

SUÁREZ, M; BANDEIRA, L. (Orgs.). Violência, gênero e crime no Distrito Federal. Brasília: Editora UnB, 1999.

TEMPLE, D.; CHABAL, M. La réciprocité et la naissance des valeurs humaines. Paris: L'Harmattan, 1995.

VIGARELLO, G. História do estupro. Rio de Janeiro: Jorge Zahar, 1999.

WACQUANT, L. J. D. A zona. In: BOURDIEU, P. (Coord.). A miséria do mundo. Petrópolis: Vozes, 1997. p. 177-202.

\section{NOTAS}

* Graduada em História e Mestre em Antropologia Social pela URGS. Doutora em Ciências Sociais pela UNICAMP. Bolsista PRODOC no PPGAS-UFSC. Endereço eletrônico: mottaflavia@bol.com.br.

${ }^{1}$ Cruz e Souza é o mais notável nome da literatura catarinense. Foi também o mais notável entre os "negros em terra de brancos" e sua poesia traz a marca da exclusão social que a cor de sua pele impôs à sua vida e sua versão pessoal da escola literária simbolista. 
${ }^{2}$ Apresentado no II Seminário Internacional Educação Intercultural, Gênero e Movimentos Sociais: Identidade, Diferença, Mediações UFSC, Florianópolis, em abril de 2003. Agradeço aos membros do grupo, especialmente pelos comentários, a Bernadette Grossi dos Santos, Analba Brazão Teixeira, Rozeli Porto e, pelo incentivo à publicação, Laura Moutinho. Mais recentemente este texto contou com as leituras de Cláudia Fonseca, Jurema Brites e Marcos Lanna, aos quais agradeço também.

${ }^{3}$ Ver Sahlins (1997).

${ }^{4}$ Mesmo a região onde fica sua casa já vem assumindo o perfil residencial - recebendo "bichosgrilo", estudantes e migrantes pobres em busca de moradia mais barata (em relação aos preços dos balneários referidos, mas também têm recebido empreendimentos imobiliários como condomínios horizontais e loteamentos destinados à classe média. Uma moradora de um dos loteamentos vizinhos ao segmento residencial familiar de Deca exultou quando lhe contamos sobre a prisão de Jairo, dizendo que ela e suas amigas já não faziam mais caminhadas naquela região por medo dos estupros que lá vinham ocorrendo. Disse que não se surpreendia nada em saber que um informante nosso, sendo seu vizinho, estivesse envolvido em crimes porque “aquilo lá é uma bandidagem”, enumerou vários exemplos dessa "bandidagem”, alegando inclusive que lojas de móveis usados ali localizadas são, na verdade, pontos de receptação de furtos.

${ }^{5}$ Gíria que significa "chato", mas que Lulu e uma outra jovem informante (21 anos) usam com o sentido de inútil, "traste", imprestável.

${ }^{6}$ Para um exemplo de um episódio que "nos remete à síntese existente no Brasil entre violência e troca de dádivas (e uma determinada ideologia de generosidade)", ver Lanna (1995, p. 91).

${ }^{7}$ Em outro texto Godbout refere, de passagem, a violência, mais uma vez para negá-la enquanto dádiva, novamente a partir de uma pergunta: "O que é dádiva? De modo negativo, entende-se por dádiva tudo o que circula na sociedade que não está ligado nem ao mercado, nem ao Estado (redistribuição), nem à violência física. De modo mais positivo, é o que circula em prol do ou em nome do laço social" (GODBOUT, 1998, p. 44).

${ }^{8}$ Ver Silva (1997) e o artigo de Aureliano Biancarelli: "Estupro é o delito que mais causa injustiça”. São Paulo, Folha de São Paulo, 16/08/1998.

${ }^{9}$ Através de denúncia junto à comissão de direitos humanos da $\mathrm{OAB}$, que levou à intervenção da Corregedoria de Polícia no caso, a qual, embora agindo rapidamente, não confirmou a denúncia, mas sustou as agressões físicas ao acusado. Para uma discussão acerca de direitos humanos como uma noção que envolve categorias historicamente construídas que determinam aqueles que são merecedores desses direitos, "os mais e os menos humanos", ver Fonseca e Cardarello (1999). 
${ }^{10}$ Tendo, inclusive, tentado suicídio.

${ }^{11}$ Que, no caso de Jairo, além de "social" e "econômica" é também racial. No seu aspecto mais geral, e talvez mais profundo, a figura de Jairo evoca Rickey, o hustler do gueto negro de Chicago entrevistado por Wacquant (que, como não poderia deixar de ser, procede a uma análise em que o "personagem" aparece devidamente contextualizado social e historicamente): "ele é o produto da passagem do limite de uma lógica de exclusão socioeconômica e racial secular que afeta de perto ou de longe todos os moradores do gueto" (WACQUANT, 1997, p. 184).

12 Sobre o estupro visto como "morte psíquica" pelas sensibilidades contemporâneas, ver Vigarello (1999).

${ }^{13}$ E talvez pudéssemos falar em "violências culturais", a exemplo da violência que representa a exposição de um estilo de vida hedonista (encarnado pelo turista) calcado no lazer, num "ócio ostensivo" e na aquisição de bens materiais que representam um padrão de vida inatingível para a maioria daqueles que referimos aqui como nativos - talvez essa violência tenha um preço, uma contrapartida!

${ }^{14}$ Mediante pagamento de módica mensalidade.

${ }^{15}$ A incapacidade das turistas de preverem os riscos à sua segurança lembra a sensação de invencibilidade que Cook parecia experimentar em sua "caminhada em direção à morte". Cook chegou a escrever em seu diário pessoal: "Esses riscos são os companheiros inevitáveis do homem que faz descobrimentos" (Sahlins, 1997, p. 168).

${ }^{16}$ Ou melhor, se prolonga, se mantém, já que ele nunca se fecha.

${ }^{17} \mathrm{Ou}$ ainda: criam mal-entendidos culturalmente construídos, semelhantes àqueles tratados por Sahlins (1997).

${ }^{18}$ Jurema Brites (2004), por exemplo, realizou etnografia sobre as relações cotidianas de encontro/ enfrentamento de classe na sociedade brasileira, ao descrever as relações entre empregadas domésticas e seus empregadores. Analisando narrativas de furtos, mostra uma gramática de opressão-subalternidade extremamente tensa e violenta que raramente se expressa abertamente, mas teatraliza a constrangedora abundância de uns e miserabilidade de outros.

${ }^{19} \mathrm{O}$ caráter sexual da violência interclasse e inter-racial, entretanto, não é novidade na história da sociedade brasileira. $\mathrm{O}$ caso aqui analisado representa na verdade uma inversão da tradicional situação em que, desde os tempos da escravidão, o branco se apropria sexualmente do corpo da mulher negra socialmente subordinada. 


\section{ABSTRACT}

Race, gender, class and rape: exclusion and violence in relations between locals and tourists in Florianópolis, Santa Catarina, Brazil

This study discusses the case of Jairo. Born in Florianópolis, black, a domestic servant's son, Jairo experiences lifelong economic, social, and racial exclusion: during childhood he drops out of school in the fourth grade before even learning how to read and write; as a teenager, working in construction and odd jobs, he fails to adapt to the world of work and gradually gets involved in misdemeanors (drug use, petty theft). At 19 he is arrested (beaten), tried, and convicted to 17 years in prison for having assaulted, robbed, and raped a white middle-class tourist in the dunes near his house, when she was walking back from the beach. Even while agreeing that the case illustrates one of the most barbarous forms of violence against women, and one that must be combated, the current article focuses on another issue. This particular case highlights a given dimension of relations between locals and foreigners in the paradisiacal beach landscape of Florianópolis, namely the violent side of these relations, in which race, culture, class, and gender aspects converge (and in some cases accumulate).

Key words: Race; culture; class; gender; rape; violence. 